\title{
Researching Effects of Drawing on Prevalence of Carpal Tunnel Syndrome with Architecture Students
}

\author{
Esra Dogru ${ }^{1}$, Mehmet Harun Kizilci ${ }^{2}$, Fatma Duman ${ }^{1}$, Nilufer Cetisli Korkmaz ${ }^{1}$, Ozden Canbay ${ }^{1}$, \\ Bircan Yucekaya ${ }^{1}$
}

${ }^{1}$ School of Physical Therapy and Rehabilitation, Mustafa Kemal University, Hatay, Turkey

${ }^{2}$ Malatya School of Health, Department of Physical Therapy and Rehabilitation, Inonu University, Malatya, Turkey

\section{Email address:}

esradogru001@hotmail.com (E. Dogru),harun044@hotmail.com (M. H. Kizilci),fduman@mku.edu.tr (F. Duman), niluferc75@yahoo.com (N. Cetisli Korkmaz), ozdencanbay@hotmail.com (O. Canbay), bircanyucekaya@hotmail.com (B. Yucekaya)

\section{To cite this article:}

Esra Dogru, Mehmet Harun Kizilci, Fatma Duman, Nilufer Cetisli Korkmaz, Ozden Canbay, Bircan Yucekaya. Researching Effects of Drawing on Prevalence of Carpal Tunnel Syndrome with Architecture Students. Science Journal of Public Health.

Vol. 3, No. 2, 2015, pp. 237-241. doi: 10.11648/j.sjph.20150302.22

\begin{abstract}
Objectives: Carpal tunnel syndrome is an important peripheral neuropathy in architecture students because of the working and writing position for long hours. The purpose of this study was assesing and comparing carpal tunnel syndrome signs in the first grade and fourth grade architecture students. Methods: 30 first grade and 30 fourth grade students were included in the study. Each patient was assessed with a questionnaire, muscle tests, pain assesment and examination signs (Phalen Test, Tinnel Test, Durkan Signs). Results: Some of the muscle test performances were better in first grade students compared to fourth grade students. There were more pain complaints with fourth grade students $(p=0.003)$. There were statistically significant differences between the two groups in Phalen's $(p=0.001)$, Durkan's $(p=0.001)$ and Tinel's signs $(p=0.044)$. The fourth grade students' signs were positive while first grade students' were negative. Conclusions: Working long hours with wrong position of the hand causes carpal tunnel syndrome in architecture students. Ergonomic interventions, such as keyboard modifications, positioning the wrist is in a straight position and wrist exercises were recommended to prevent carpal tunnel syndrome in architecture students.
\end{abstract}

Keywords: Architecture, Carpal Tunnel Syndrome, Occupational Therapy

\section{Introduction}

Carpal Tunnel Syndrome (CTS) is one of the most common peripheral neuropathies, caused by compression of the median nerve as it passes through the carpal tunnel into the wrist. In the carpal tunnel, the median nerve lies immediately beneath the palmaris longus tendon and anterior of the flexor tendons. Conditions which decrease the tunnel's size, or swelling, compress the median nerve against the transverse ligament bounding the tunnel's roof ${ }^{(1,2) \text {. }}$

Approximately $1.6 \%$ of adults experience symptoms consistent with CTS. CTS characterized by paresthesia and pain in the distribution of the median nerve, and occasionally weakness which leads functional impairment ${ }^{(2-5)}$. In most cases of carpal tunnel syndrome (80\%), no factors promoting the disease development can be identified. In such cases, the disease is decalred as idiopathic CTS. However, numerous factors that promote the development of CTS have been identified. They can be classified as; comorbid diseases (diabetes, hypothyroidism, and rheumatoid arthritis), anatomical factors, age, gender, race, body weight, body mass index, substance abuse (smoking, exacerbation of alcoholic neuropathy), hormonal factors and work-related factors ${ }^{(6)}$.

Work-related factors referred to performing repeated activities requiring wrist flexion and extension, microinjuries and vibrations ${ }^{(2,7)}$. The physical factors implicated and extensively studied in relation to occupational CTS include repetition, force, posture, external pressure, and vibration. Repetition is the most widely recognized risk factor for occupational CTS. In epidemiological studies high repetition is defined either by the frequency of the task or the percentage of time spent on repetitive work. A high repetitive job is defined as one which involves the repetitive use of awkward wrist movements lasting less than 30 s or when more than $50 \%$ of work time is spent performing tasks that 
involve repetitive awkward wrist movements (1). Occupational hazards mostly found in staff use repetitive hand movements while working like dentists $\left({ }^{8,9,10)}\right.$.

Several studies examining carpal tunnel pressure (CTP) in healthy subjects indicate that the greatest increase in CTP occurs during the wrist flexion and extension. In an experimental study in healthy volunteers, Rempel et al measured intra-compartmental pressures using a saline filled catheter placed in the carpal tunnel. The authors noted the highest mean intra-compartmental pressure $(55 \mathrm{mmHg})$ during full supination and 90 degree metacarpophalangeal (MCP) joint flexion and lowest pressure at 45 degrees of pronation and 45 degrees of MCP joint flexion. The authors speculated that the increased CTP at full supination and at 90 degree MCP flexion changes the orientation of the tendons, thereby, increasing the volume of the carpal tunnel predisposing to CTS. The authors suggested that the lowest pressures achieved by position should be considered in job and tool design ${ }^{(11,12,13)}$.

CTS is one of the most widely recognized occupational health conditions; particularly in industries where the work involves high force/pressure repetitiveness and vibrating tools. The occupations that have high risks were grinders, cashiers, meat packers, sewing machine workers, aircraft engineers, grocery store workers, and small part assembly liners ${ }^{(1)}$. Since architectures not within this risks occupational groups we aimed to work with the students of architecture department in college.

\section{Material-Method}

\subsection{Subjects}

The study was done in Mustafa Kemal University, Faculty of Architecture with first and fourth grade students. 30 subjects of the participant were first grade and 30 subjects were fourth grade students. Participants signed a consent form before attending the study. Students who have systemic disease, wrist fracture or surgery for CTS were excluded. First grade and fourth grade students who accepted participating the study and older than 18 were included.

\subsection{Procedure}

This study is conducted between November 2013- January 2014. Evaluation was done utilizing thorough the literature. At the beginning of the evaluation, data about demographic characteristics of students were collected. Student's working time in a day, working with a special table or using PC for drawing, having difficulties because of numbness while drawing, dropping materials, having problems in pinching little materials, sleeping problems because of numbness tingling, wrist rigidity in the morning, thenar atrophy, thumbindex- middle - ring fingers' numbness were qustioned. Pronation, supination, wrist flexor, wrist extansor, ulnar deviation, radial deviation muscle strength were assessed by manual muscle test. Phalen, Durkan and Tinel Sign Tests were evaluated to observe CTS signs. Pain in the arm was assessed with Visual Analogue Scale (VAS).

\subsection{Tests}

1. Phalen's Maneuver: Phalen's maneuver or the wrist flexion test described as positive when full flexion of the wrist for 60 seconds cause paresthesia in the territory of the median nerve. Patients with CTS, numbness and tingling developes within 1 to 2 minutes. Therefore, if the patient does not experience symptoms within approximately 3 minutes, the test is considered as negative ${ }^{(12,13)}$.

2. Tinel Sign: The Tinel Sign was adopted in the early 1950 's to detect the nerve compression. In this test, the examiner taps lightly over the distribution of the median nerve at the distal wrist. Development of tingling or discomfort in the fingers supplied by the median nerve constitutes a positive sign ${ }^{(14)}$.

3. Durkan's Carpal Compression Test: This test relies upon direct pressure applied externally by the examiner over the carpal tunnel to increase the pressure. It can performed by pressing with the examiners' thumbs or with a device designed to apply a standard amount of pressure ${ }^{(15)}$.

\subsection{Statistical Analysis}

The statistical analysis was performed using SPSS 20.0 for Windows Analysis Programme. Descriptive statistic was done for demographic data. Differences between the two groups were analyzed with Chi-square test.

\section{Results}

There were 60 students who met the criteria, with an average age of $21.28 \pm 2.08$ years and 24 of the students were female. 30 students who met the criteria in the first class (20.21 \pm 2.149 years), and 30 students in the fourth class ( $22.48 \pm 1.22$ years) between 18 - 27 years old were included in the study. Students' mean of age was similar in the both group.

The average time of drawing was 2.8 hours in a day. However, fourth grade students were drawing more than first grade students $(\mathrm{p}=0.001) .18$ students from first grade and 12 students from fourth grade used special drawing table. 2 students from first grade and 29 students from fourth grade class were using PC while drawing; and the rest of them were drawing by hand.

11 students from first grade and 23 students from fourth grade had difficulties while drawing because of numbness and tingling. There was a statistically significant difference between the two groups. Fourth grade students had more difficulties $(p=0.002)$. This situation caused dropping the materials in 7 students from first grade and 8 students from fourth grade class. However, 4 from first grade and 6 from fourth grade students had problems with pinching little materials. There was no significant difference between two grades.

Numbness cause sleeping problems in 1 student from first grade and 8 students from fourth grade students. Fourth grade 
students had more sleeping problems $(\mathrm{p}=0.011)$.

Morning wrist rigidity problems were seen with 2 from first grade students and 10 from fourth grade students. There was a statistically significant difference between the two groups. Fourth grade students had more rigidity problems $(\mathrm{p}=0.01)$.

Only 1 fourth grade student had thenar atrophy.

Wrist flexor-extensor-supinator-pronator, finger flexor, ulnar deviation and radial deviation muscle test performances were better in first grade students compared to fourth grade students (Table1).

There were statistically significant differences between the two groups in Phalen's Maneuver $(p=0.001)$, Durkan's Carpal Compression Test $(\mathrm{p}=0.001)$ and Tinel's Sign $(\mathrm{p}=0.044)$. Fourth grade students' signs were positive while first grade students' were negative (Table 2).

22 of the 60 students had pain during the activity (average VAS score was 5.72) and inactivity (average VAS score was 2.54). There were more pain complaints with fourth grade students $(\mathrm{p}=0.003)$.

Table 1. Muscle Power Analysis (Lovett's Manual Muscle Test)

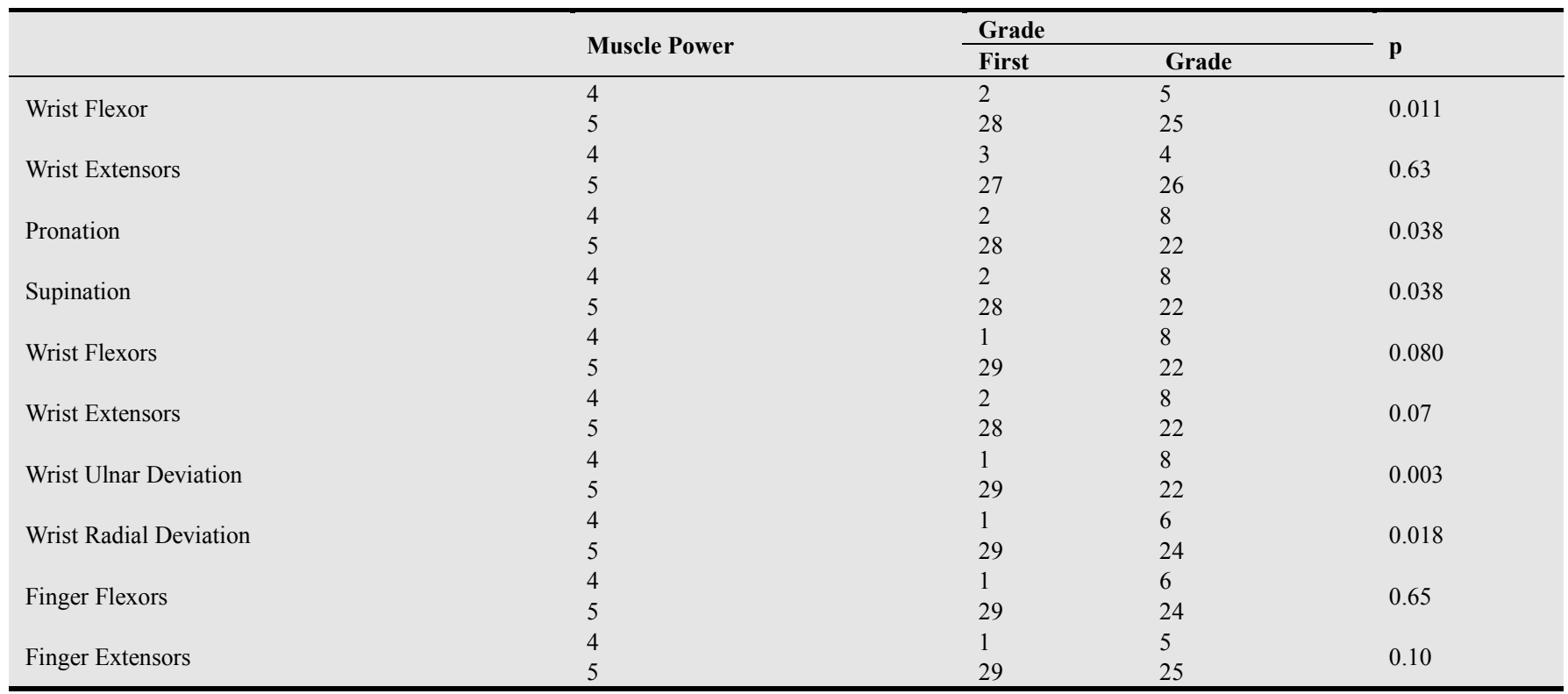

Table 2. Aggravation Tests Signs

\begin{tabular}{|c|c|c|c|c|}
\hline & Tests Sions & & & \\
\hline & Tests Signs & First & Fourth & $\mathbf{p}$ \\
\hline \multirow{2}{*}{ Phalen's Maneuver } & Positive & 0 & 16 & \multirow{2}{*}{0.001} \\
\hline & Negative & 30 & 14 & \\
\hline \multirow{2}{*}{ Durkan's Carpal Compression Test } & Positive & 0 & 15 & \multirow{2}{*}{0.001} \\
\hline & Negative & 30 & 15 & \\
\hline \multirow{2}{*}{ Tinel's Sign } & Positive & 1 & 6 & \multirow{2}{*}{0.044} \\
\hline & Negative & 29 & 24 & \\
\hline
\end{tabular}

\section{Discussion}

It was found that fourth grade students were drawing for more hours than the first grade students in a day. Pronation, supination, wrist flexor-extensor, ulnar deviation, radial deviation muscle strength of first grade students were higher than fourth grade students in the Faculty of Architecture. In fourth grade students tingling-needling complaints in the first three fingers and half of the ring finger spreading of tinglingneedling to forearm, reporting difficulties while drawing and sleeping because of the numbness; hand rigidity-stiffness sensation in the morning and wrist pain were found to be more significant compared to first grade students. We concluded that it was related to carpal tunnel syndrome symptoms and overuse, high force, repetitive work of wrist because of drawing for long hours.
Brain and colleagues attributed the symptoms of CTS to spontaneous median nerve compression in the carpal tunnel ${ }^{(1)}$. The compression was believed to be mediated by several factors such as exertion strain, overuse, hyperfunction, repeated or prolonged wrist extension, prolonged grasping of tools, and unaccustomed manual work ${ }^{(16)}$. Einhorn and Leddy estimated an incidence of $1 \%$ in the general population and in 5\% of workers in certain industries which require repetitive use of the hands and wrists ${ }^{(14)}$.

Experimental studies have shown a higher incidence of CTS in workers who have to done high force and repetitive work compared to workers who have not ${ }^{(17,18)}$. Silverstein et al examined the association between high force/repetitive movements and CTS among 652 workers from 39 jobs from seven different industrial areas. The authors noted prevalence of 5.6\% among workers in high force and high repetitive jobs compared to $0.6 \%$ among workers in low force and low 
repetitive jobs. The authors showed occupation was a risk factor only when it is done with high force and high repetition. High repetitiveness seems to be a greater risk factor than high force but neither was statistically significant alone ${ }^{(17)}$.

In our study we found that fourth grade students (97\%) use computer more than first grade students $(7 \%)$ while drawing. We saw connection between using computer and CTS symptoms. CTS is an important problem among computer professionals. Mohamed Ali studied prevalence of CTS among computer professionals and risk factors among 648 subjects. The prevalence of CTS was found to be $13.1 \%$. He declared subjects with over 8 years of computer work, over 12 hours of work per day and system administrators were at a higher risk for CTS. Flexed or extended hand position had higher risk for CTS. Higher risk for CTS was higher exposure to computer work. Ergonomic considerations are important in facilitating proper positioning of hand while working with a computer ${ }^{(19,20)}$.

Rempel at al. investigated the effects of typing at different wrist postures on carpal tunnel pressure of the right hand with 20 healthy subjects in a laboratory .They found that changes in wrist flexion/extension angle and radial/ulnar deviation angle independently altered carpal tunnel pressure; wrist deviations in extension or radial deviation were associated with an increase in pressure. The activity of typing independently elevated carpal tunnel pressure relative to holding the hand in the same static posture ${ }^{(21) .}$

Manktelow and his colleagues studied on 964 subject who have work-related CTS and found out that $46 \%$ of workers experienced moderate to severe pain, $47 \%$ had moderate to severe numbness, and $40 \%$ had difficulty in grasping and using small objects ${ }^{(22)}$. In our study wrist pain was found to be higher in fourth grade students than first grade students. The pressure on the carpal tunnel while drawing for long hours in the wrong position causes pain.

In the treatment of carpal tunnel syndome many conservative and surgical methods are used. Surgical treatment for CTS involves opening the carpal tunnel, the tunnel in which the median nerve passes through the wrist. Nonsurgical treatments include medications, exercises, splinting and ergonomic interventions. Werner at al. invetigated effect of nocturnal splinting on workers whom with CTS symptoms. Workers with active CTS symptoms tended to benefit from 6 weeks nocturnal splinting trial, and the benefits were still evident at the 1-year follow-up ${ }^{(23)}$. Pratelli at al. compared effect of laser therapy (LT) and fascial manipulation (FM) on CTS. The group that received FM showed a significant reduction in subjective pain perception and an increased function assessed by Boston Carpal Tunnel Questionnaire at the end of the treatment and follow-up. The group that received LT showed improvement in the Boston Carpal Tunnel Questionnaire at the end of the treatment but the improvement level was not sustained at the three month follow-up. They stated that FM is a valid alternative treatment for CTS ${ }^{(24)}$.

Ergonomic interventions, such as keyboard modification, using the hand while the wrist is positioned in a straight position. In this neutral wrist position the tunnel through which the median nerve passes is at its most capacious. This position is expected to cause least pressure on the median nerve theoritically. While there some ergonomic advise for protecting wrist from CTS, there is no strong evidence for or against the use of ergonomic keyboards for the treatment of CTS ${ }^{(25)}$. The difference that found between the groups in our study was associated only with repetitive wrist movement.

Sleep disturbance were higher in fourth grade students in our study. Patel at al. signified that patients with CTS reported greater experience with a wide range of sleep difficulties and individual patients with CTS were characterized by having multiple sleeping complaints compared to those without CTS ${ }^{(26) .}$

Ergonomics is the science of designing the job to fit the worker, rather than physically forcing the worker's body to fit the job ${ }^{(27) .}$ More ergonomic designs should be made for all jobs that work with their hands like architects. Nonergonomic working conditions cause carpal tunnel syndrome in architects.

\section{References}

[1] Aroori S, Spence RA. Chronic pain after hernia surgery--an informed consent issue. The Ulster medical journal. 2007;76(3):136-40.

[2] Palmer KT. Carpal tunnel syndrome: the role of occupational factors. Best practice \& research Clinical rheumatology. 2011;25(1):15-29.

[3] Tanaka S, Wild DK, Seligman PJ, Behrens V, Cameron L, Putz-Anderson V. The US prevalence of self-reported carpal tunnel syndrome: 1988 National Health Interview Survey data. American journal of public health. 1994;84(11):1846-8.

[4] Dawson DM. Entrapment neuropathies of the upper extremities. The New England journal of medicine. 1993;329(27):2013-8.

[5] Solomon DH, Katz JN, Bohn R, Mogun H, Avorn J. Nonoccupational risk factors for carpal tunnel syndrome. Journal of general internal medicine. 1999;14(5):310-4.

[6] Zyluk A. Is carpal tunnel syndrome an occupational disease? A review. Polish orthopedics \& traumatology. 2013;78:121-6.

[7] Latko WA, Armstrong TJ, Franzblau A, Ulin SS, Werner RA, Albers JW. Cross-sectional study of the relationship between repetitive work and the prevalence of upper limb musculoskeletal disorders. American journal of industrial medicine. 1999;36(2):248-59.

[8] Atroshi I, Gummesson C, Johnsson R, Ornstein E.Diagnostic properties of nerve conduction tests in population-based carpal tunnel syndrome.BMC Musculoskelet Disord. 2003 May 7;4:9. Epub 2003 May 7.

[9] Haghighat A, Khosrawi S, Kelishadi A, Sajadieh S, Badrian H Prevalence of clinical findings of carpal tunnel syndrome in Isfahanian dentists. Adv Biom.. 2009 Feb;116(2):97-101ed Res 2012;1:13. 
[10] Tandheelkd T, Krom MC, Krom CJ, Spaans F.Carpal tunnel syndrome: diagnosis, treatment, prevention and its relevance to dentistry.

[11] Rempel D, Bach JM, Gordon L, So Y. Effects of forearm pronation/supination on carpal tunnel pressure. The Journal of hand surgery. 1998;23(1):38-42.

[12] Seror P: Phalen's test in the diagnosis of carpal tunnel syndrome. J Hand Surg Br 1988;13:383-385.

[13] Vargas-Busquets MA: Historical commentary: the wrist flexion test (Phalen sign). J Hand Surg Am 1994;19: 521.

[14] Somaiah Aroori, Roy AJ SpenceCarpal tunnel syndrome The Ulster Medical Society, 2008; 77 (1) 6-17

[15] Filip Georgiew Provocative tests used in the diagnosis of carpal tunnel syndrome Medical Rehabilitation 2007, 11 (4), $7-17$

[16] Brain WR, Wright AD. Spontaneous compression of both median nerves in the carpal tunnel. Lancet 1947; 1: 277- 82

[17] Silverstein BA, Fine LJ, Armstrong TJ. Occupational factors and carpal tunnel syndrome. Am J Ind Med 1987; 11(3): 34358

[18] Stetson DS, Silverstein BA, Keyserling WM, Wolfe WA, Albers JW. Hypothesis relating cumulative trauma to the median nerve with sub- clinical nerve conduction deficits. Am J Ind Med 1995; 27(2): 309-10

[19] K. Mohamed Ali B.W.C. Sathiyasekaran Computer Professionals and Carpal Tunnel Syndrome (CTS) International Journal of Occupational Safety and Ergonomics (JOSE) 2006, Vol. 12, No. 3, 319-325
[20] Isolani L, Bonfiglioli R,. Raffi G.B. Violante F.S. Different case definitions to describe the prevalence of occupational carpal tunnel syndrome in meat industry workers. Int Arch Occup Environ Health (2002) 75: 229-234

[21] Rempel DM; Keir PJ; Bach JM. Effect of wrist posture on carpal tunnel pressure while typing. J Orthop Res 2008 Sep; 26(9):1269-1273

[22] Manktelow RT, Binhammer P, Tomat LR, Bril V, Szalai JP. Carpal tunnel syndrome: cross-sectional and outcome study in Ontario workers. The Journal of hand surgery 2004: 29: 307317.

[23] Werner RA, Franzblau A, Gell N. Randomized controlled trial of nocturnal splinting for active workers with symptoms of carpal tunnel syndrome. Arch Phys Med Rehabil. 2005 Jan;86(1):1-7.

[24] Pratelli E, Pintucci M, Cultrera P, Baldini E, Stecco A, Petrocelli A, Pasquetti P. J Bodyw Mov Ther. Conservative treatment of carpal tunnel syndrome: Comparison between laser therapy and fascial manipulation 2015 Jan;19(1):113-8.

[25] O'Connor D, Page MJ, Marshall SC, Massy - Westropp N. Ergonomic positioning or equipment for treating carpal tunnel syndrome. Cochrane Database of Systematic Reviews 2012, Issue 1. Art. No.: CD009600.

[26] Patel J.N, Steven J. McCabe, Myers J. Characteristics of sleep disturbance in patients with carpal tunnel syndrome. Hand (N Y). 2012 Mar; 7(1): 55-58.

[27] U.S. Department of Labor Occupational Safety and Health Administration, Ergonomics: The Study of Work, OSHA 3125 2000 